\begin{tabular}{c} 
International Journal of Engineering \& Technology, 7 (3) (2018) 1067-1071 \\
International Journal of Engineering \& Technology \\
SPC \\
Website: $\begin{array}{c}\text { ww. sciencepubco.com/index.php/IJET } \\
\text { doi: } 10.14419 / \text { ijet.v7i3.11403 } \\
\text { Research paper }\end{array}$ \\
\hline
\end{tabular}

\title{
Tracking self-assembly morphology of cationic peptide analogues using turbidimetric- potentiometric titration
}

\author{
Huey Ling Tan ${ }^{1}$, Ying Pei Lim ${ }^{1}$, Mohomad Sufian So’aib ${ }^{1}$ \\ ${ }^{1}$ Faculty of Chemical Engineering, Universiti Teknologi MARA, 40450 Shah Alam, Malaysia \\ *Corresponding author E-mail: hueyling@salam.uitm.edu.my
}

\begin{abstract}
Peptide amphiphiles are promising molecular materials for drug delivery systems and regenerative medicine through formation of wellordered nanostructures. Rationally designed self-associating synthetic peptide analogues containing arginine (FEFEFRFR) and lysine (FEFEFKFK) were studied to understand the effect of $\mathrm{pH}$ and side chain interactions and its influence on the resulting nanostructure formation. Changes in structural conformation in bulk were followed by turbidimetric-potentiometric titrations with $\mathrm{pH}$ ranges from 4 to 11 and 4 to 12.6 for FEFEFKFK and FEFEFRFR respectively. Fourier Transform Infrared Spectroscopy (FTIR) was used to determine the secondary structure of the peptides while Field Emission Scanning Electron Microscopy (FE-SEM) was employed to study the morphology and dimension of higher order structures at various $\mathrm{pH}$. Turbidity results showed that both FEFEFKFK and FEFEFRFR displayed higher turbidity level when their side chains were neutralized, in which FEFEFRFR showed higher turbidity level when arginine was neutralized. Both peptides exhibited similar self-assembly behavior in solution which mainly adopted antiparallel $\beta$-sheets conformation with spherical structures of different micro-metre size when there is a net charge of +2 or -2 . FEFEFKFK was also found to form concaved disks and beads-on-a-string arrangement at $\mathrm{pH} 4$. Both the peptide analogues were capable of forming smaller aggregates in a network of spherical structure at nanoscale when the net charge was near zero. This study ultimately provides a better understanding of predicting morphology and size of surface functional modification of self-assembled polypeptides.
\end{abstract}

Keywords: Amphiphilic Peptides; $\beta$-Sheet; Secondary Structure; Spontaneous Self-Assembly; Turbidimetric Titration

\section{Introduction}

A major focus in the current development in biotechnology is the fabrication of new molecular materials which also known as biobased materials using natural building blocks such as amino acids, nucleic acids and phospholipids [1,2]. The basis of molecular selfassembly is the intrinsic polymerization at the early stage and the systems lie at the interface between molecular biology, chemistry, polymer science, materials science, and engineering [3]. Bio-molecular self-assembly shows promising results and leads to a significant role in the production of new bio-based materials for various applications including drug delivery systems, regenerative medicine nanofabrication, bio-mineralisation and tissue engineering [4, 5]. Employment of peptide building blocks as bio-materials based product has many potential applications [3] due to their propensity to self-assemble into highly ordered structures at different length scales $[1,6]$. FF, $\mathrm{A}_{6} \mathrm{D}$ (AAAAAAD), $\mathrm{V}_{6} \mathrm{D}$ (VVVVVVD), $\mathrm{G}_{8} \mathrm{DD}$ (GGGGGGGGDD), KV 6 (KVVVVVV) [7 - 9] can self-assemble into solid nanotubes through aromatic or aliphatic amino acid residues that lead to the formation of spherical structure, nanotube and nanowire $[2,10]$.

The design and synthesis of novel biomaterials require a better understanding of how supramolecular architectures assemble in nature [11]. Chemical complementary, structural compatibility and stability are important concerns in molecular self-assembly [3]. Peptide stability can be enhanced by introducing more intra-disulfide bonds, designing more hydrophobic cores, or modifying the surface charges [12,13]. The choice of building block for biomaterials applications is also crucial to allow the design of structures with controlled geometry in different environmental conditions [1]. Formation of complex multi component three-dimensional structures is facilitated by non-covalent interactions, such as hydrogen bonds, ionic interactions, hydrophobic forces, van der Waals interactions and stacking interactions $[2,3]$. The dominant factor found to affect the stability is $\mathrm{pH}$, which controls net charge on the peptide surface, and subsequently affects the aggregation behaviour. Altering $\mathrm{pH}$ implies instantaneous changes in the protonation states of the involved species, which can be used as a powerful tool for the controlled and reversible assembly of nanoparticles. The peptide analogues investigated in this work were based on four different amino acids: phenylalanine (Phe, F), glutamic acid (Glu, E), lysine (Lys, K) and arginine (Arg, R). Phe is a non-charged, hydrophobic amino acid. This amino acid was used to modify the overall hydrophobicity of the octapeptides. Arg and Lys are hydrophilic amino acids and have side chains that are positively charged. Arg has higher crystal contact propensities than Lys with $\mathrm{p} K$ as of 12.4 and 10.5, respectively [14]. All the hydrophobic and hydrophilic amino acids of these two oligopeptides are organised in alternating sequence and are characterised by charge distribution of $(--++)$, as shown in Fig.1. Turbidimetric-potentiometric titration was used to gain insights into peptide properties in bulk solution. The turbidity in the peptide solution reflected an increase in self-assembled aggregates. The contribution of peptide hydrophobicity and side 
chain interactions to net peptide-peptide interaction was probed by changing the $\mathrm{pH}$ of the solution. Samples were taken at different $\mathrm{pH}$ according to the turbidity profile for FTIR measurements and FESEM imaging. Specifically, this study is focusing on tracking the intrinsic property of the peptide analogues' morphology and stability while maintaining the temperature, peptide concentration and medium composition.
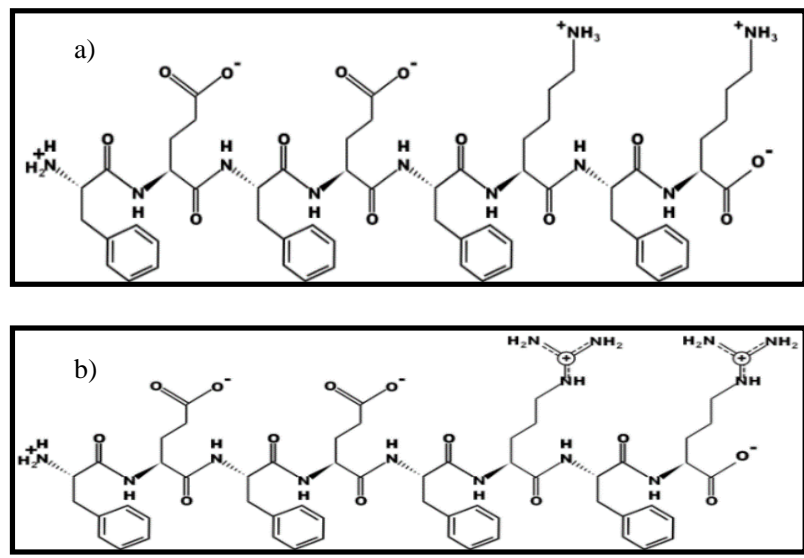

Fig. 1: Molecular structure and charge distribution of a) FEFEFKFK and b) FEFEFRFR.

\section{Materials and methods}

\subsection{Materials and samples preparation}

FEFEFKFK and FEFEFRFR were synthesized based on the standard Fmoc-based, solid-phase peptide synthesis strategy and purified by reverse-phase high performance liquid chromatography indicating high purity of at least $98 \%$. Filtered $(0.2 \mu \mathrm{m}$ from VWR $)$ deionised water was used as a blank in all experiments. For turbidimetric titration measurements, $0.1 \mathrm{~g} / \mathrm{L}$ peptide solution was prepared by dissolving the peptide in filtered deionised water $(18 \mathrm{M} \Omega-\mathrm{cm})$ under mild agitation. In addition, diluted $(0.05 \mathrm{M})$ or concentrated $(2$ M) solutions of hydrochloric acid $(\mathrm{HCl})$ or sodium hydroxide $(\mathrm{NaOH})$ was used to titrate the peptide solutions.

\subsection{Turbidimetric-potentiometric titrations}

The details of the experimental procedure have been reported previously [15]. In short, turbidity measurements were carried out using a colorimeter probe (Brinkmann, PC 950 with $2 \mathrm{~cm}$ path length fibre optics) at $490 \mathrm{~nm}$. The transmittance (T) mode was used and the turbidity was reported as $100-\mathrm{T} \%$, where the turbidity reading was compared to a calibrated $100 \%$ transmittance reading of filtered solvent as a blank. A Fisher brand Hydrus $300 \mathrm{pH}$ meter was used to monitor the changes of solution $\mathrm{pH}$. Mild agitation $(100 \mathrm{rpm})$ was applied to the solution during the measurements to ensure good mixing. Titration was started from $\mathrm{pH} 4$ to 11 or 12.6 , depending on the side chain $\mathrm{pK}$ as of the hydrophilic amino acids in the sequence. Each peptide titration was carried out with small volume of titrant $(\mathrm{HCl}$ or $\mathrm{NaOH})$ corresponding to a $\mathrm{pH}$ change close to 0.2 , and the turbidity value was recorded. For each peptide sequence, five samples were taken at different $\mathrm{pH}$ including the highest and lowest turbidity for FTIR and FE-SEM characterization.

\subsection{Fourier transform infrared spectroscopy (FTIR)}

FTIR (Pelkin-Elmer Spectrum One) was used to determine the secondary structure of the peptide. $30 \mu \mathrm{L}$ of peptide solutions was dropped on the $\mathrm{CaF}_{2}$ crystal with a $50 \mu \mathrm{m}$ Teflon spacer. Measurements were performed at room temperature with the wave number ranging from 515 to $4000 \mathrm{~cm}^{-1}$. Before placing the sample on the crystal, the air ventilation located above the $\mathrm{CaF}_{2}$ was switched on for ensuring the air within the surrounding area was clean.

\subsection{Field emission scanning electron microscopy (FE- SEM)}

Samples for FE-SEM were recorded on a JEOL JSM-6510 electron microscope. The magnifications used to study the peptide morphology and dimensions were varied according to the practicalities from as low as $600 \mathrm{x}$ to $40000 \mathrm{x}$. A small volume $(10 \mu \mathrm{L})$ peptide solution was pre-treated with osmium-tetra oxide. Then, the samples were placed on the stage of the FE-SEM and inserted into the vacuum chamber to be viewed.

\subsection{Digital image analysis}

Diameter of the structure was measured with the aid of Image J 1.43 (NIH) imaging software using FE-SEM images. The analysis was carried out by setting the measure scale to suit with the 2D FE-SEM image. Other detail and required measurements were set up in this step. Next, the boundaries of each structure on the image were detected. The boundary can easily be detected from binary images or other types, which were obtained from the thresholded SEM images. Measurements were performed on ordered structures only.

\section{Results and discussion}

\subsection{Turbidity profile}

Peptide self-assembly morphology and the possible nanostructure formation were followed using a wide $\mathrm{pH}$ range of 4 to 12.6. The side chain $\mathrm{pKa}$ values of the free glutamic acid $(\mathrm{E})$, lysine $(\mathrm{K})$, and arginine (R) were 4.25, 10.53 and 12.4, respectively. Effect of different amino acids on charge states was investigated by neutralizing glutamic acid $(\mathrm{E})$, lysine $(\mathrm{K})$ and arginine $(\mathrm{R})$ when the $\mathrm{pH}$ of the peptide solutions was reduced to below 4.25 and raised to above 10.53 (for FEFEFKFK) or 12.4 (for FEFEFRFR). The transmission percentage from the colorimeter probe determines the turbidity of the peptide in solution, which reflected the changes in aggregation size and quantity as a function of $\mathrm{pH}$. Fig.2a depicted a turbidity profile of an initially clear, soluble solution of FEFEFKFK. The turbidity level was measured by increasing the $\mathrm{pH}$ of the peptide solution from 3.5 to 11 . The peptide solution was held for $\sim 1$ minute at each $\mathrm{pH}$ value. The first and second turbidity maxima with respect to $\mathrm{pH}$ were observed at around $\mathrm{pH} 6.5$ and 10.7 respectively, indicating the formation of peptide aggregates. Higher turbidity maxima found at $\mathrm{pH} 6.5$ was mainly due to the net charge on the peptide is zero. At low and higher $\mathrm{pH}$, a net charge of +2 or -2 is preventing the peptide from forming aggregates.

FEFEFRFR showed significantly higher turbidity level (Fig.2b) compared to FEFEFKFK. Arg and Lys were mostly exposed to protein surfaces [16] and play important roles in protein stability by forming ionic interactions and hydrogen bonds in the proteins as well as by interacting with water molecules [17]. Although they both function as basic residues, the Arg residues provide more stability to the structure than Lys owing to its geometric structure. First turbidity maxima were observed at $\mathrm{pH} 6.1$, while a drastic increase in turbidity to 22.7 was found at $\mathrm{pH} 12$. Formation of first turbidity maxima outside the region where the net charge for both the peptide is zero is most likely due to $\mathrm{pKa}$ shift [15]. 

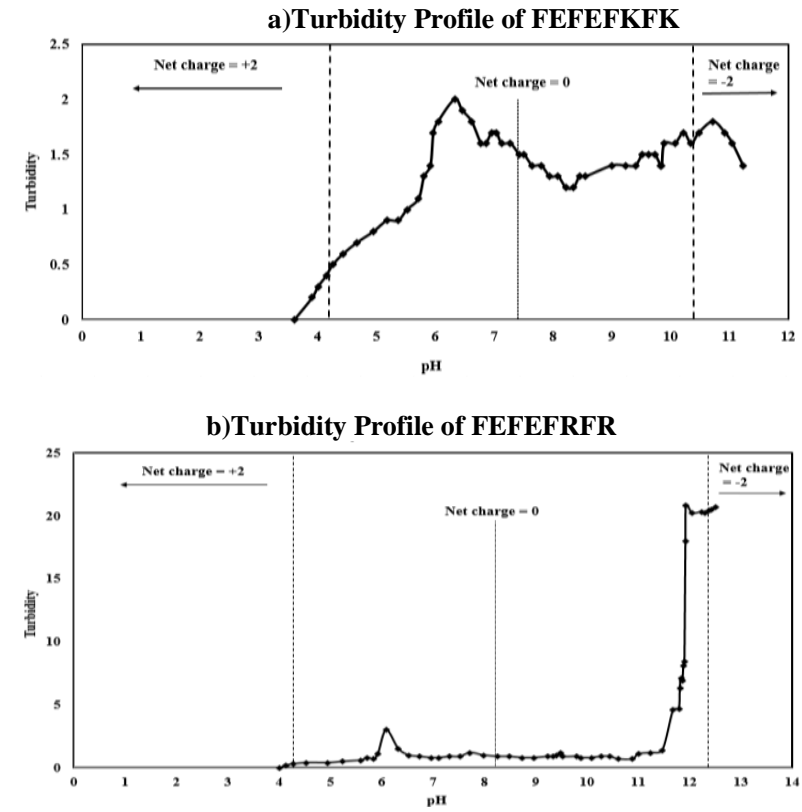

Fig.2: Turbidity profile of a) FEFEFKFK and b) FEFEFRFR as a function of pH. First turbidity maxima was observed around $\mathrm{pH} 6.5$ for both the peptides. FEFEFRFR showed significantly higher second turbidity maxima at pH 12.

\subsection{Secondary structure analysis of peptide aggregates}

Five peptide solutions were taken at different $\mathrm{pH}$ values based on the turbidity profiles for FTIR measurements to determine the secondary structure and intramolecular interactions of the peptide structures. There are 9 primary bands related to the structure of proteins, which are amide A, amide B and amide I-VII bands. Of these, the amide I and II bands are the two most prominent vibrational bands of the protein backbone [18, 19]. Fig. 3 and 4 show amide A $\mathrm{B}$ and $\mathrm{I}$ bands in IR spectra of FEFEFKFK and FEFEFRFR at different pHs. In Fig.3, one strong adsorption between 3323 to 3336 $\mathrm{cm}^{-1}$ representing $\mathrm{NH}_{2}$ stretching of primary amines and the strong absorption of amide I ( $\mathrm{C}=\mathrm{O}$ stretching) at $1635 \mathrm{~cm}^{-1}$ are correlated with antiparallel $\beta$-sheet formation [20,21]. The weaker absorption at $1635 \mathrm{~cm}^{-1}$ with increasing $\mathrm{pH}$ implying that antiparallel $\beta$-sheet structure is getting less dominant. Disappearance and reappearance of antiparallel $\beta$-sheet structure at $\mathrm{pH} 9$ and 10.72 indicating FEFEFKFK has a structural transition during higher order structure formation.

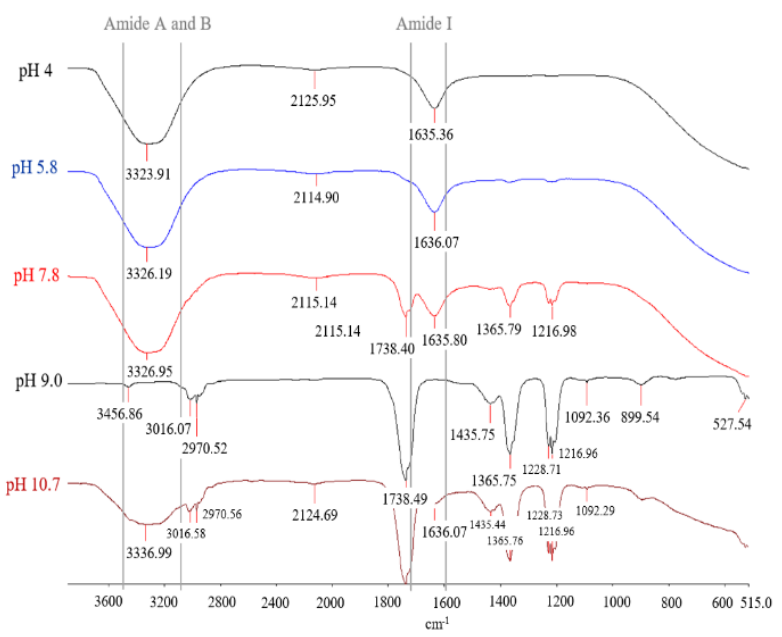

Fig. 3: FTIR spectroscopy results of FEFEFKFK ranging from $\mathrm{pH} 4$ to 10.72. Band formation in the region of $1615-1691 \mathrm{~cm}^{-1}$ was observed in peptide solutions at $\mathrm{pH} 4,5.7,7.8$ and 10.7 indicating the existence of $\beta$ sheet conformations.
In Fig.4, a strong absorption between 3315 to $3321 \mathrm{~cm}^{-1}$ also implying $\mathrm{NH}_{2}$ stretching of primary amines when FEFEFRFR has a net charge of +2 , between 0 to -2 or -2 , that is at $\mathrm{pH} 4,10.4$ and 12.6. Amide I band is commonly used to interpret changes in protein structure and conformation. Amide A and B bands, demonstrating N-H stretching frequency levels, are also important for the interpretation of the H-bonding ability of peptides. It is well established that the non-hydrogen bonded $\mathrm{N}-\mathrm{H}$ is due to higher energy bands, while the lower energy bands correspond to intramolecularly hydrogen bonded $\mathrm{N}-\mathrm{H}[22,23]$. Large absorption peaks seen at amide $\mathrm{A}$ and $\mathrm{B}$ regions at $\mathrm{pH}$ ranging from 4 to 12.6 indicates the presence of hydrogen bonding of the $\mathrm{N}-\mathrm{H}$ group. A weaker absorption at $1636 \mathrm{~cm}^{-1}$ and a minor band at $3456 \mathrm{~cm}^{-1}$ indicate a small population of non-H-bonded N-H (out-of-phase stretching vibrations) near neutral $\mathrm{pH}$ suggesting that antiparallel $\beta$-sheet structure is getting less dominant, a case that is valid to both peptides [24]. This is most likely due to the more prominent influence of hydrophobic phenylalanine $(\mathrm{F})$ in reducing peptide solubility in aqueous media during peptide self-association when the net charge is zero or near zero [10].

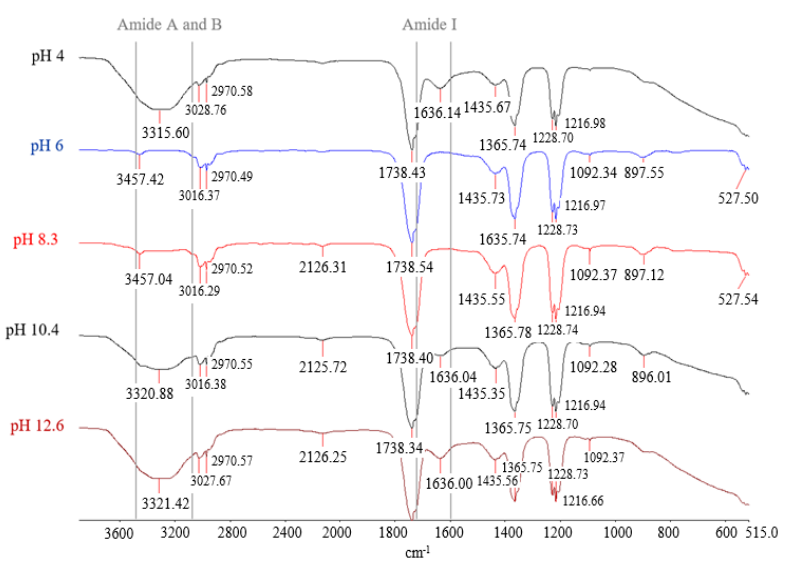

Fig. 4: FTIR spectroscopy results of FEFEFRFR. $\beta$-sheet structure was

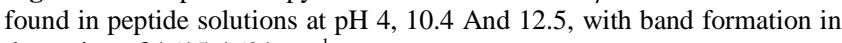
the region of $1615-1691 \mathrm{~cm}^{-1}$.

\subsection{Peptide morphology analysis}

Interesting molecular self-assembly and nano-structural transformation of both the peptides in solution were observed. The shapes, sizes and morphological transformation of the peptide nanostructures were investigated using Field Emission Scanning Electron Microscopy (FE-SEM) and Image J. FEFEFKFK and FEFEFRFR formed diverse micro- and nanometer-sized structures at different $\mathrm{pH}$ with their inherent amphiphilic character. SEM images showed that both the FEFEFKFK and FEFEFRFR were capable of forming isolated microspheres (Fig.5a1 and 5f) when there is net charge presence at acidic or basic $\mathrm{pH}$. These spherical entities have a diameter ranging from 1.2 to $3.2 \mu \mathrm{m}$ and 2.3 to $6.5 \mu \mathrm{m}$ respectively. Interestingly, concave disks (Fig.5a2) with average size of $3.5 \mu \mathrm{m}$ and beads-on-a-string arrangements (Fig.5a3) were also found in FEFEFKFK solutions. SEM images clearly depict the presence of smaller and larger spherical aggregates. These larger spherical aggregates could be formed by the fusion of small spherical structures (Fig.5a1). FTIR results showed the presence of $\beta$-sheet conformation in the structures. Dong and colleagues [18] reported similar results in which amide I spectra was observed in globular proteins in aqueous solutions. 


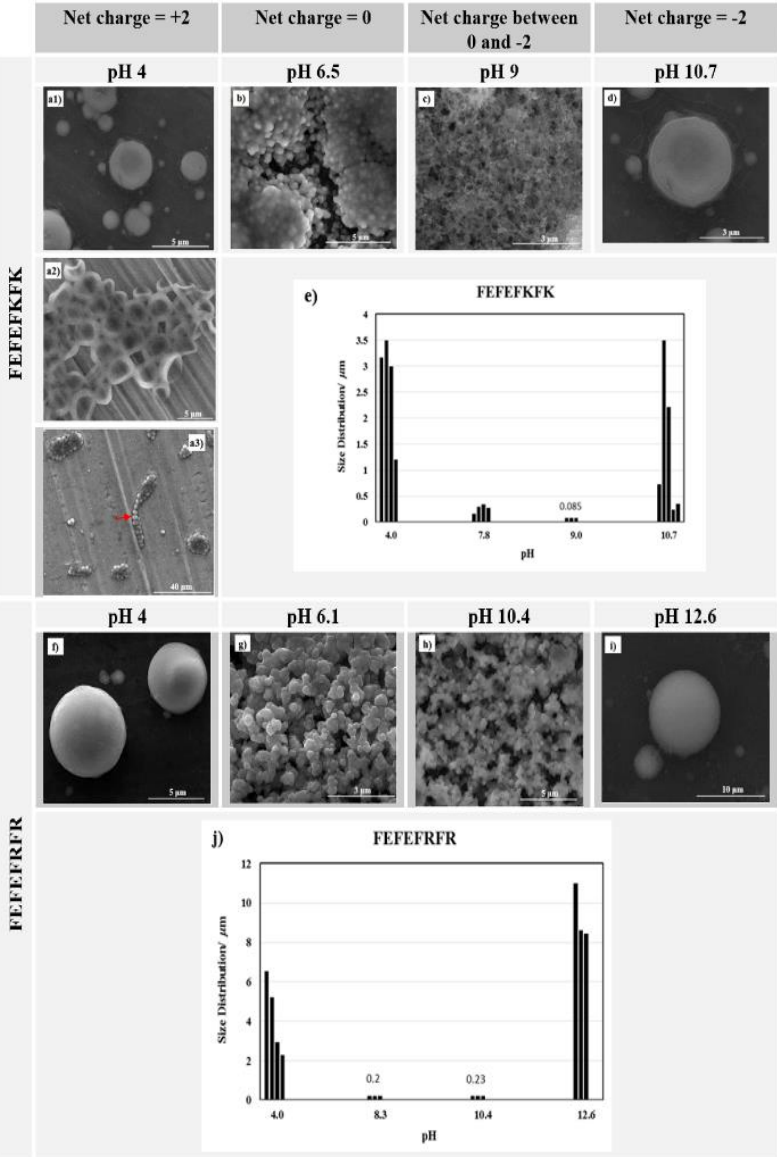

Fig. 5: SEM images of FEFEFKFK and FEFEFRFR showing morphological diversity at various $\mathrm{pH}$. FEFEFKFK peptide solution under $\mathrm{pH} 4$ displaying spherical entities (a1), concave disks (a2), and beads-on-a-string arrangements (a3). Higher density of nanospheres were formed when the net charge of the peptides was zero (b) or near zero (c). FEFEFKFK formed spherical structures again when net charge is presence. FEFEFRFR formed spherical structures (f and i) and spherical network like morphology ( $g$ and h) at $200 \mathrm{~nm}$. Size distribution of the micro- or nanometer sized structures for both the peptides are depicted in (e) and (j).

Near neutral $\mathrm{pH}$, FEFEFKFK and FEFEFRFR have a net charge of zero and aggregates with higher density were formed. $\mathrm{Mi}$ crographics analysis revealed that FEFEFKFK has undergone morphological changes, in which the spherical entities were found to afford a network-like morphology (Fig.5b) with average pore size of $0.3 \mu \mathrm{m}$. Peptide spherical structure was found to decrease by 10 fold to $0.25 \mu \mathrm{m}$. At $\mathrm{pH} 9$, pore size ranging from 0.1 to $0.3 \mu \mathrm{m}$ was found in more compact network-like nanospheres with an average size of $85 \mathrm{~nm}$ (Fig.5c). Isolated microspheres (Fig.5d) with size ranging from 0.23 to $3.61 \mu \mathrm{m}$ were formed once again when there was a net charge presence on the peptide.

FEFEFRFR formed more consistent spherical aggregates of $0.2 \mu \mathrm{m}$ at $\mathrm{pH} 6.1$ and 10.4 (Fig.5g, 5h) with larger pore size ranging from 0.45 to $0.63 \mu \mathrm{m}$ compared to FEFEFKFK. FEFEFRFR displayed very high turbidity at $\mathrm{pH} 12$ when arginine $(\mathrm{R})$ was neutralised and formed much larger spherical structure ranging from 8.5 to $11 \mu \mathrm{m}$ (Fig.5i). Basic $\mathrm{pK}$ a values of Lys and Arg are 10.53 and 12.48 respectively, at these $\mathrm{pH}$ values the amino groups of Lys and Arg were neutralized leaving both the peptides to carry a net charge of -2 . Results indicate that the influence of electrostatic interactions was strong in forming nanostructure of different shapes and sizes [25]. Positive charge is delocalized within the $\pi$-bonded system of the side chain guanidinium ion in Arg allows interactions in three possible directions through its three asymmetrical nitrogen atoms $\left(\mathrm{N}^{\varepsilon}, \mathrm{N}^{\eta 1}, \mathrm{~N}^{\eta 2}\right)$, whereas only one direction of interaction is allowed by the basic functional group of Lys [26]. This enables Arg to form stronger electrostatic interactions than the interactions generated by Lys through the formation of a higher number of salt bridges and hydrogen bonds compared to Lys. These effects have been demonstrated indirectly by comparing the salt-bridge numbers generated by Arg and Lys in a number of proteins as well as by analyzing the Arg to Lys ratio and salt-bridges in thermophilic and mesophilic proteins [27].

The importance of charge is also reported by Mandal and coworkers, in which the charged amphiphilic block copolypeptides are able to form stable spherical structure such as vesicles in aqueous solution [28]. The ionic interactions formed by Arg can be more stable than those of Lys by generating more stable ionic interactions, particularly under basic $\mathrm{pH}$, due to the higher $\mathrm{pKa}$ of Arg than Lys [29, 30]. The difference in the ionic interactions on the protonated states of Arg and Lys has been demonstrated by a theoretical estimation based on their side chain $\mathrm{pKa}$. According to the study, $20 \%$ of the Arg side chains were protonated whereas most of the Lys side chains were deprotonated at $\mathrm{pH} 13$ [29]. Therefore, peptide sequence containing Arg results in an increasingly positive charged environment, resulting negatively charged hydrophilic head of the glutamic acid (E) binds to positively charged Arg side chains more favourably than in FEFEFKFK, hence higher turbidity in FEFEFRFR solution.

The importance of aromatic side chain interactions as pivotal structural elements in the self-assembly of nanofibers/ nanotubes has been discussed in many works, however, the exact mechanism for aromatic stabilisation is still unknown. Stacking interactions, mainly T-shaped or parallel displaced, are important to the stability of the nanostructure. Other studies have suggested that the self-assembly of aromatic peptides is mainly due to the hydrophobic character [31]. Phenylalanine (Phe, F) has a strong tendency to form fibrillary structure [32], however, such conformation was not observed in this work, excluding that the aromatic rings of Phe are involved in rigid and fixed structures with chiral orientation, as observed for aromatic peptides forming fibers. Certain degree of freedom in the rotation of the aromatic ring of the Phe residues could be influencing the $\pi-\pi$ interactions, rendering weaker backbone $\mathrm{H}$ bonds and making the microsphere structure founded on a high number of weak and transient interactions [33].

\section{Conclusion}

Mutual dependence of side chain interactions and $\mathrm{pH}$ in short amphiphilic self-assembled peptide analogues is discussed. Results showed that FEFEFKFK and FEFEFRFR favoured the formation of spherical entities when the peptides have net charge, which mainly consists of antiparallel $\beta$-sheet conformation. Higher density of nanospheres was formed when both the peptides has decreasing net charge near neutral $\mathrm{pH}$. FEFEFRFR has higher turbidity at $\mathrm{pH} 12$ due to negatively charged hydrophilic head of the Glu binds more favourably to positively charged Arg side chains than in FEFEFKFK in increasingly positive charged environment. The fundamental of this research will help to understand the common features of these peptides and the knowledge will in return guide future design and application.

\section{Acknowledgement}

This work was funded by the Ministry of Higher Education Malaysia, under the Research Acculturation Grant Scheme, RAGS (600RMI/RAGS 5/3 (21/2012)).

\section{References}

[1] Aline FM, Alberto S (2010) Engineering peptide based biomaterials: structure, properties and application. Chimica Oggi: Chemistry Today 28(1), 34-38

[2] Shamsudeen H, Tan HL (2015) Self-assembly of peptide amphiphiles: molecularly engineered bionanomaterials. Advanced Materials Research 1113, 586-593. https://doi.org/10.4028/www.scientific.net/AMR.1113.586.

[3] Zhang S and Altman M (1991) Peptide self-assembly in functional polymer science and engineering. Reactive and Functional Polymers 41, 91-102 https://doi.org/10.1016/S1381-5148(99)00031-0. 
[4] Vauthey S, Steve S, Gong H, Watson N, Zhang S (2002) Molecular self-assembly of surfactant-like peptides to form nanotubes and nan$\begin{array}{lll}\text { ovesicles. } & \text { PNAS } & \text { 99(8), }\end{array}$ https://doi.org/10.1073/pnas.072089599.

[5] Sadatmousavi P, Mamo T, Chen P (2012) Diethylene glycol functionalized self-assembling peptides nanofibers and their hydrophobic drug delivery potential. Acta Biomater 8(9), 3241-3250. https://doi.org/10.1016/j.actbio.2012.05.021.

[6] Koki M, McElheny D, Tereshko V, Hilyard A, Gawlak G, Yan S, Koide A, Koide S (2006) Atomic structures of peptide self-assembly mimics. Proc Natl Acad Sci USA 103(47), 17753-17758. https://doi.org/10.1073/pnas.0606690103.

[7] Yan XH, He Q, Wang K, Duan L, Cui Y, Li J (2007) Transition of cationic dipeptide nanotubes into vesicles and oligonucleotide delivery. Angew Chem Int Ed 46, 2431-2434. https://doi.org/10.1002/anie.200603387.

[8] Vauthey S, Santoso S, Gong H, Watson N, Zhang SG (2002) Molecular self-assembly of surfactant-line peptides to form nanotubes and nanovesicles. PNAS 99(8), 5355-5360. https://doi.org/10.1073/pnas.072089599.

[9] Zhang SG, Zhao XJ (2004) Design of molecular biological materials using peptide motifs. J Mater Chem 14, 2082-2086. https://doi.org/10.1039/b406136e.

[10] Hong Y, Legge RL, Zhang S, Chen P (2003) Effect of amino acid sequence and $\mathrm{pH}$ on nanofiber formation of self-assembling peptides EAK16-II and EAK16-IV. Biomacromolecules 4(5), 1433-1442. https://doi.org/10.1021/bm0341374.

[11] Kyle S, Aggeli A, Ingham E, McPherson MJ (2009) Production of self-assembling biomaterials for tissue engineering. Trends in Bio-

423-433. https://doi.org/10.1016/j.tibtech.2009.04.002

[12] Tigerstrom A, Schwarz F, Karlsson G, Okvist M, Alvarez-Rua C Maeder D, Robb FT, Sjolin L (2004) Effects of a novel disulfide bond and engineered electrostatic interactions on the thermostability of azurin. Biochemistry 43(39), 12563-12574. https://doi.org/10.1021/bi048926x.

[13] Northey JG, Di Nardo AA, Davidson AR (2002) hydrophobic core packing in the SH3 domain folding transition state. Nat Struct Biol 9(2), 126-130. https://doi.org/10.1038/nsb748.

[14] Sirram S, Govindan R, Sun-Gu L (2013) Study on the effect of surface lysine to arginine mutagenesis on protein stability and structure using green fluorescent protein. PLOS ONE 7(7), e40410

[15] Tan HL, Curtis R (2017) Inter-relation of surface tension and optical turbidity in self-assembled peptide amphiphiles. Biointerface Research in Applied Chemistry 7(1), 1913-1920.

[16] Kumar S, Tsai C-J, Nussinov R (2000) Factors enhancing protein thermostability. Protein Eng 13(3), 179-191. https://doi.org/10.1093/protein/13.3.179.

[17] Strickler SS, Gribenko AV, Gribenko AV, Keiffer TR, Tomlinson J, Reihle T, Loladze VV, Makhatadze GI (2006) Protein stability and surface electrostatics: a charged relationship. Biochemistry 45(9), 2761-2766. https://doi.org/10.1021/bi0600143.

[18] J. Kong, S. Yu (2007) Fourier transform infrared spectroscopic analysis of protein secondary structures. Acta Biochim Biophys Sin 39(8), 549-559. https://doi.org/10.1111/j.1745-7270.2007.00320.x.

[19] Haris P I, Severcan F (1999) FTIR spectroscopic characterisation of protein structure in aqueous and non-aqueous media. J Mol Catal B: Enzym, 7(1-4) 207-221. https://doi.org/10.1016/S1381-1177(99)00030-2.

[20] Bozkurt O, Haman Bayari S, Severcan M, Krafft C, Popp J, Severcan F (2012) Structural alterations in rat liver proteins due to streptozotocin-induced diabetes and the recovery effect of selenium: fourier transform infrared microspectroscopy and neural network study. J Biomed Opt 17(7), 0760231-0760238. https://doi.org/10.1117/1.JBO.17.7.076023.

[21] Sokalingam S, Raghunathan G, Soundrarajan N, Lee SG (2012) A study on the effect of surface lysine to arginine mutagenesis on protein stability and structure using green fluorescent protein. PLoS ONE 7(7), e40410. https://doi.org/10.1371/journal.pone.0040410.

[22] Dado GP, Gellman SH (1994) Intermolecular hydrogen bonding in derivatives of beta-alanine and gamma-amino buryric-acid model studies for the folding of unnatural polypeptide backbones. J Am Chem Soc 116 1054-1062. https://doi.org/10.1021/ja00082a029.

[23] Dinesh B, Vinaya V, Raghothama S, Balaram P (2013) C12-helix development in $(\alpha \gamma) \mathrm{n}$ sequences-spectroscopic characterisation of Boc-[Aib- $\gamma 4$ (R) Val]-OMe oligomers. Eur J Org Chem 17, 3590-3596 https://doi.org/10.1002/ejoc.201300264.

[24] Piasek Z, Urbanski T (1962) the infrared absorption spectrum and structure of urea. Bulletin De L'academie Polonaise Des Sciences 10(3), 113 120.

[25] Mu Q, Jang G, Zhou H, Fourches D, Tropsha A, Yan B (2014) Chemical basis of interactions between engineered nanoparticles and biological systems. Chem Rev 114(15), 7740-7781. https://doi.org/10.1021/cr400295a.

[26] Borders J, Broadwater JA, Bekeny PA, Salmon JE, Lee AS (1994) A structural role for arginine in proteins: Multiple hydrogen bonds to backbone carbonyl oxygens. Protein Sci 3, 541-548. https://doi.org/10.1002/pro.5560030402.

[27] Musafia B, Buchner V, Arad D (1995) Complex salt bridges in proteins: Statistical analysis of structure and function. J Mol Biol 254, 761-770. https://doi.org/10.1006/jmbi.1995.0653.

[28] Mandal D, Shirazi AN, Parang K (2014) Self-assembly of peptides to nanostructures. Org Biomol Chem 12(22), 3544-3561. https://doi.org/10.1039/C4OB00447G.

[29] Sokalingam S, Raghunathan G, Soundrarajan N, Lee SG (2012) A study on the effect of surface lysine to arginine mutagenesis on protein stability and structure using green fluorescent protein. PLoS ONE 7(7), e40410. https://doi.org/10.1371/journal.pone.0040410.

[30] Turunen O, Vuorio M, Fenel F, Leisola M (2002) Engineering of multiple arginines into the Ser/Thr surface of Trichoderma ressei endo-1,4-b-xylanase II increases the thermotolerance and shifts the $\mathrm{pH}$ optimum towards alkaline $\mathrm{pH}$. Protein Eng 15, 141-145. https://doi.org/10.1093/protein/15.2.141.

[31] Bemporad F, Calloni G, Campioni S, Plakoutsi G, Taddei N, Chiti F (2006) Sequence and structural determinants of amyloid fibril formation. Acc Chem Res 39(9), 620-627. https://doi.org/10.1021/ar050067x.

[32] C. H. Gorbitz (2006) the structure of nanotubes formed by diphenylalanine, the core recognition motif of alzheimer's beta-amyloid polypeptide. Chem Commun 22, 2332-2334. https://doi.org/10.1039/B603080G.

[33] Scelsi A, Bochicchio B, Smith A, Saiani A, Pepe A (2015) Nanospheres from the self-assembly of an elastin-inspired triblock peptide. RSC Adv 5, 95007-95103. https://doi.org/10.1039/C5RA21182D. 